\title{
Efficiency enhancement of ternary blend organic photovoltaic cells with molecular glasses as guest acceptors
}

\author{
Tham Adhikari, ${ }^{a}$ Sanyasi Rao Bobbara, ${ }^{b}$ Jean-Michel Nunzi, ${ }^{a, b, *}$ Olivier Lebel ${ }^{\mathrm{c}, *}$ \\ ${ }^{a}$ Department of Chemistry, Queens University, Kingston, Ontario, Canada \\ ${ }^{\mathrm{b}}$ Department of Physics, Engineering Physics and Astronomy, Queens University, Kingston, Ontario, Canada \\ ${ }^{c}$ Department of Chemistry and Chemical Engineering, Royal Military College, Kingston, Ontario, Canada
}

*Corresponding Author. E-mail address: nunzijm@queensu.ca (J.M. Nunzi); Olivier.Lebel@rmc.ca (O. Lebel).

\begin{abstract}
Previously reported glass-forming perylenediimide (PDI-glass) and diketopyrrolopyrrole (DPP-glass) acceptors were used as ternary components to modulate the morphology and electron transport properties of bulk heterojunctions composed of the polymer blend poly(3hexythiophene) $(\mathrm{P} 3 \mathrm{HT})$ and $[6,6]$-phenyl- $\mathrm{C}_{61}$-butyric acid methyl ester $\left(\mathrm{PC}_{61} \mathrm{BM}\right)$. Both ternary acceptors show strong absorption in the visible range and energy levels intermediate between that of P3HT and PCBM. In the blends, both amorphous materials occupy the interface between P3HT and PCBM domains without significantly altering film morphology. The incorporation of $20 \%$ PDI-glass and 15 $\%$ DPP-glass in ternary blend devices has resulted in conversion efficiency enhancements of $38 \%$ and $36 \%$, respectively. Additionally, the incident photon to electron conversion efficiency of the ternary devices of these materials was increased with additional photocurrent between $660-750 \mathrm{~nm}$, indicating that these materials efficiently contribute to light harvesting. This justifies the efficiency enhancements via the charge transfer mechanism. Furthermore, these ternary devices show high stability towards both moisture and oxygen.
\end{abstract}

Keywords: Organic photovoltaic cells, Bulk heterojunction, Ternary Blend, Charge Transfer, Donor-Acceptor Interface full potential. Besides designing alternative donor and acceptor materials with improved performance, several other approaches were employed to enhance the efficiency of

\section{Introduction}

In recent years, organic photovoltaic (OPV) cells have attracted increased attention as potential sources of renewable energy over traditional inorganic solar cells due to their simplicity, flexibility, light weight, cost effectiveness, and processablity. ${ }^{1-7}$ However, the commercialization of organic PV cells is limited due to their relatively low power conversion efficiency and low stability as compared to silicon-based solar cells. ${ }^{8-10}$ Traditionally, common materials used in OPV cells are poly (3-hexylthiophene) (P3HT) and [6,6]-phenyl- $\mathrm{C}_{61}$-butyric acid methyl ester (thereafter referred to as PCBM). Although both materials are still considered benchmarks, various materials with significantly higher performances have been developed in recent years, ${ }^{11-12}$ though often at a significant increase in cost. P3HT therefore retains certain advantages over other donor polymers such as low cost, high crystallinity, high hole mobility, and ease of synthesis. For these reasons, while P3HT:PCBM bulk heterojunction OPV cells can reach conversion efficiencies around $5 \%,{ }^{13}$ attempting to improve the performance of OPV cells using P3HT is still the object of research. However, P3HT only absorbs photons in the blue and green parts of the spectrum with wavelength below $650 \mathrm{~nm}$, leading to low short-circuit current and low PCE. ${ }^{14}$

The two principal limitations of OPV cells consist in their narrow absorption range, which leads to a significant portion of the visible and near-infrared spectrum not being harvested, and the control over the morphology of the bulk heterojunction, which is often suboptimal and leads to various defects that prevent the active layers from operating at their organic photovoltaic cells, including solvent additives, solvent vapor treatment, the incorporation of metal nanoparticles in the active layer, and improving morphology for better charge transport. ${ }^{2,15-17}$ The fabrication of tandem OPV cells by stacking two or more subcells with different donor or acceptor materials has also been attempted for enhancing the light absorption for OPV cells. However, this approach is limited because of its complexity. ${ }^{18-19}$ Therefore, it is necessary to investigate a simpler and effective method to enhance the efficiency of OPV cells.

Ternary blend OPV cells constitute a simple alternative approach that can also expand the absorption spectra by incorporating another organic material as guest sensitizer. ${ }^{20}$ Generally, ternary blend OPV cells can contain an active layer with either two donors and one acceptor, or two acceptors and one donor. In both cases, they are believed to follow the same mechanisms: the energy transfer, charge transfer, parallellinkage, and alloy models. ${ }^{19,21-23}$ Various types of materials such as nanoparticles, low bandgap polymers and small molecules can be incorporated as sensitizers, which typically show a complementary absorption spectrum to the polymerbased blend. Small molecules are the most promising sensitizers for ternary blends because they allow the tuning of both the absorption and the morphology of the active layer by modifying their molecular structure. ${ }^{24}$

There are several examples reported in the literature of ternary blend OPV cells, both based on two donors and one acceptor, or with one donor and two acceptors. ${ }^{24-26}$ Since fullerene derivatives are often used as acceptors, and show 
very weak absorption in the visible range, the ternary blend approach becomes especially appealing in these cases because the additional light harvesting by the third component can increase cell performance significantly. In one example, an efficiency enhancement of $20 \%$ was reported by incorporating an additional non-fullerene acceptor with strong absorption in both the visible and near-infrared ranges in the P3HT:PCBM blend, ${ }^{25}$ while a recent study using a fullerene deriative as ternary acceptor in a PBDB-T:IT-M blend has shown a $13 \%$ enhancement to reach a maximal conversion efficiency of $12.2 \% .{ }^{26}$ However, the crystalline nature of such additional components can disrupt the morphology of the blend, either upon deposition of the blend or upon prolonged operation, thereby causing a loss of efficiency. ${ }^{25}$

Amorphous materials constitute an appealing alternative because they conveniently avoid most pitfalls associated with crystallinity. ${ }^{16}$ Although most small molecules inevitably converge towards the thermodynamically favored crysalline state, there exists a small group of small-molecule compounds, called molecular glasses or amorphous molecular materials, that are capable of remaining amorphous for indefinite periods of time. ${ }^{27}$ Molecular glasses are appealing because they are suitable materials for forming high-quality thin films, while retaining the advantages related to monodisperse species. ${ }^{28-29}$ Both our group ${ }^{30-32}$ and other groups ${ }^{33-35}$ have demonstrated that molecular glasses could be used successfully in organic photovoltaics with both donors and acceptors, and by blending both homogeneously as an amorphous active layer. Additionally, molceular glasses were shown to be suitable as an interfacial layer in perovskite PV cells, leading to an enhancement of $39 \%$ by using a glassforming perylenediimide (PDI) derivative. ${ }^{36}$ In the context of ternary blend OPV cells, glass-forming materials are especially appealing as ternary components, because they can be expected to locate at the interface between the donor and acceptor domains without perturbing their respective crystalline morphology, thereby providing more pathways to extract charges while preserving the supramolecular architecture of the active layer.

Herein, molecular glasses were used for the first time in ternary blend OPV cells based on P3HT/PCBM. Inverted devices were fabricated by incorporating variable concentrations of either PDI-glass or DPP-glass, leading to enhancements reaching up to $35-38 \%$. Interestingly, while DPP-glass shows significantly higher efficiencies than PDIglass when used as acceptor, their impact as ternary components were closely similar, hinting that the perforance enhancements observed are due to an improvement of the cohesion between P3HT and PCBM crystalline domains, coupled with an increased light harvesting. The devices showed high stability towards moisture or oxygen, with little performance degradation observed after 40 days under ambient conditions.

\section{Experimental}

\subsection{Materials}

The patterned Indium tin oxide (ITO) coated glasses used as substrates were purchased from Luminescence Technology Corporation, with ITO film thickness approximately $135 \pm 15$ $\mathrm{nm}$ and sheet resistance $15 \Omega \mathrm{sq}^{-2}$. Regioregular poly (3hexylthiophene) (P3HT) used as electron donor and was purchased from Rieke Metals. Molybdenum oxide used as hole transport layer and $[6,6]$-phenyl- $\mathrm{C}_{61}$-butyric acid methyl ester $\left(\mathrm{PC}_{61} \mathrm{BM}\right.$, thereafter referred to as $\left.\mathrm{PCBM}\right)$ as electron transport layer were purchased from Alfa Aesar. Zinc oxide $(\mathrm{ZnO})$ used as electron transporting material was synthesized by the sol-gel method as reported in the literature. ${ }^{31}$ PDI-glass and DPP-glass were synthesized according to previously published procedures. ${ }^{30-31}$

\subsection{Device Fabrication}

Devices were fabricated according to a previously published procedure. $^{37-38}$ Pre-patterned ITO substrates obtained from commercial sources were cleaned consecutively in an ultrasonic bath with soapy water, distilled water, acetone and isopropyl alcohol for 15 minutes each and finally dried with air. The substrates were heated on a hot plate at $80-90{ }^{\circ} \mathrm{C}$ for 20 minutes to improve the surface adhesion and wettability of ITO-glass. ${ }^{39}$ The dried substrates were further cleaned with a plasma cleaner for 15 minutes. Zinc oxide $(\mathrm{ZnO})$ precursor gel was spin-coated on cleaned ITO substrates at a rate of $3000 \mathrm{rpm}$ in air. The substrates coated with $\mathrm{ZnO}$ were baked at $160{ }^{\circ} \mathrm{C}$ for $1 \mathrm{~h}$. The thickness of zinc oxide was approximately $25-30 \mathrm{~nm}$ as measured with a Sloan Dektak II profilometer. Blend solutions of $\mathrm{P} 3 \mathrm{HT}$ and $\mathrm{PCBM}$ (total concentration $35 \mathrm{mg} / \mathrm{mL}$ ) were prepared in dichlorobenzene in 1:0.8 weight ratio and stirred for $24 \mathrm{~h}$ at $50{ }^{\circ} \mathrm{C}$. Various weight ratios of PDI-glass or DPP-glass were added to P3HT: PCBM blend solutions and stirred $2 \mathrm{~h}$ before spin-coating. The solutions were filtered through a $0.45 \mu \mathrm{m}$ poly(tetrafluoroethylene) (PTFE) filter before active layer deposition. The active layer was spin-coated at $700 \mathrm{rpm}$ and annealed at $110{ }^{\circ} \mathrm{C}$ for 30 minutes. The thickness of the active layer was measured with a Sloan Dektak II profilometer to range from 120-130 $\mathrm{nm}$. The top and bottom electrodes of the devices were cleaned with a cotton stick soaked with chloroform to make contacts. Finally, $5 \mathrm{~nm}$ of $\mathrm{MoO}_{3}$ and 100 $\mathrm{nm}$ of $\mathrm{Ag}$ were deposited with deposition rates of $0.2 \AA / \mathrm{s}$ and $1.0 \AA / \mathrm{s}$, respectively, on all the devices using a physical vapor deposition system (PVD) under high vacuum at a pressure of $7 \times 10^{-6}$ mbar. The active area of the devices was $6 \mathrm{~mm}^{2}$. The inverted device structure and energy alignment is shown in Figure 1a-b. The molecular structure of active layer components is shown in Figure 1c. 

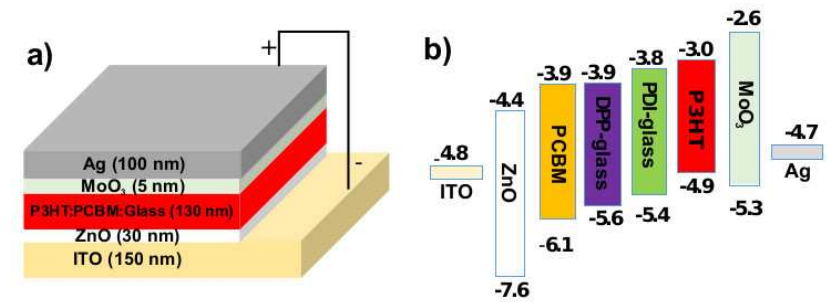

c)
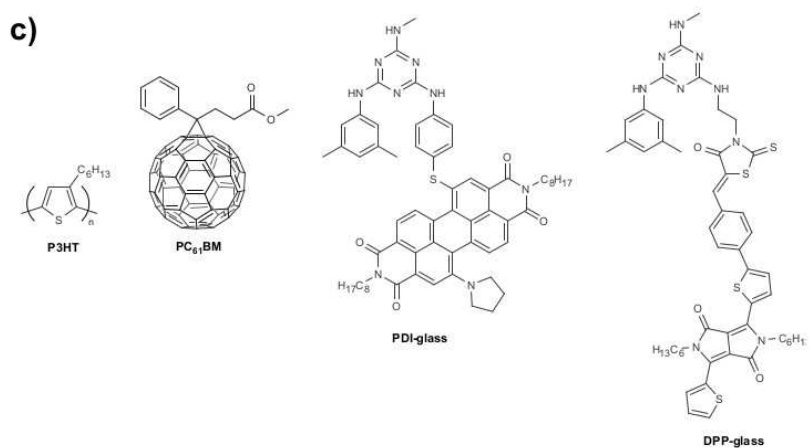

Figure 1. (a) Device architecture for inverted organic photovoltaic cells, (b) energy level diagram for the materials used in device fabrication, and (c) molecular structures for P3HT, PCBM, PDI-glass and DPP-glass.†

\subsection{Characterization}

X-ray diffraction (XRD) patterns were obtained using an Xpert Pro Philips powder X-ray diffractometer. UV-visible absorption spectra were taken using an Olid ${ }^{\circledR}$ HP8452 Diode Array Spectrometer. Fluorescence and photoluminescence (PL) spectra were measured with a USB2000-Ocean Optics spectrometer. The cyclic voltammograms were recorded using an EG\&G Model 263 potentiostat connected with three electrodes: working electrode (glassy carbon-carbon), reference electrode $(\mathrm{Ag} / \mathrm{AgCl}$ (in $3 \mathrm{M} \mathrm{NaCl})$ ) and counter or auxiliary electrode $(\mathrm{Pt})$ in $0.1 \mathrm{M}$ tetrabutylammonium hexafluorophosphate in dichloromethane at a scan rate of 50 $\mathrm{mVs}^{-1}$. The morphology of ternary blend films and control device films were characterized using an Ambios multimode Atomic Force Microscope (AFM) in tapping mode with a 300 $\mathrm{KHz}$ resonant frequency cantilever. Current density-voltage (J-V) measurements were carried out using a Keithley 4200SCS in the dark and under illumination. All the photovoltaic parameters of the inverted cells were measured under ambient conditions using a Xenon light with an intensity of 100 $\mathrm{mWcm}^{-2}$ calibrated with an AM 1.5 solar simulator. Incident photon to electron conversion efficiency (IPCE) measurements were performed in the range between 300 and $800 \mathrm{~nm}$ using a QEX7 solar cell spectral response /quantum efficiency /IPCE measurement system. The light intensity at each wavelength was calibrated with a standard single-crystal Si photovoltaic cell. The thickness of the active layer was measured with a Sloan Dektak II profilometer. Time-resolved
PL spectra were measured using a TCSPC Avalanche Photodiode Multiphoton Device Company time-resolved fluorescence spectrometer. PL decay times were measured with a spectrometer equipped with a visible photomultiplier tube using the time-corelated single photon counting (TCSPC) technique. Excitation was provided by a $1 \mathrm{MHz} 405$ $\mathrm{nm}$ picosecond laser diode. The system exhibited a time resolution of 45 ps after reconvolution with the instrument response function. The incident laser beam was kept at a power ranging from 0.1 to $1 \mathrm{~mW}$ and focused on areas on the film surface ranging between 1 to $2.5 \mathrm{~mm}^{2}$. All PL experiments were carried out under ambient conditions.

\section{Results and Discussion}

Two acceptor glasses were used as ternary components for the study: previously reported perylenediimide (PDI-glass) and diketopyrrolopyrrole (DPP-glass) derivatives, each functionalized with a mexylaminotriazine group, which is known to induce glass formation. ${ }^{30-31}$ Both compounds have been shown to act as acceptors in OPV cells with P3HT as donor, and in both cases, the compounds remain amorphous in the bulk heterojunctions. The LUMO and HOMO levels of PDI-glass are $-3.8 \mathrm{eV}$ and $-5.4 \mathrm{eV}$, respectively, whereas the LUMO and HOMO levels for DPP-glass are $-3.9 \mathrm{eV}$ and -5.6 $\mathrm{eV}$. The LUMO levels for both materials are situated in between the respective LUMO levels of P3HT and PCBM, which is essential for the electron transfer process between the donor and acceptor.

P3HT:PCBM blend films and ternary blend films containing various concentrations of either PDI-glass or DPP-glass were deposited by spin-coating, and their UV-visible absorption spectra are shown in Figure 2. As expected, the absorption spectrum for the P3HT:PCBM blend showed a main peak at $440 \mathrm{~nm}$, due to the $\pi-\pi^{*}$ transition of P3HT, and two small peaks at $335 \mathrm{~nm}(\mathrm{PCBM})$ and $605 \mathrm{~nm}$ (vibronic shoulder for P3HT). ${ }^{40-41}$ As the weight ratio of PDI-glass in the blend system increases (Figure 2a), an absorption band in the range from $620-760 \mathrm{~nm}$ corresponding to the absorption of PDIglass gradually starts appearing. This particular PDI glassforming derivative with a pyrrolidine substituent was selected in this study because of its complementary absorption with P3HT, which will result in an extended absorption spectrum, which will lead to increased light harvesting by the active layer, and a resulting increase in photocurrent generation. Additionally, a narrowing and hypsochromic shift of the P3HT absorption band can be observed with PDI-glass concentrations above $15 \%$. Similarly, as the concentration of DPP-glass in the P3HT:PCBM blend increases (Figure 2b), a shoulder near $600 \mathrm{~nm}$ appears, which is attributed to the absorption from the DPP-glass. It should be noted that the absorption band of PDI-glass is stronger than that of DPPglass at similar concentrations. 

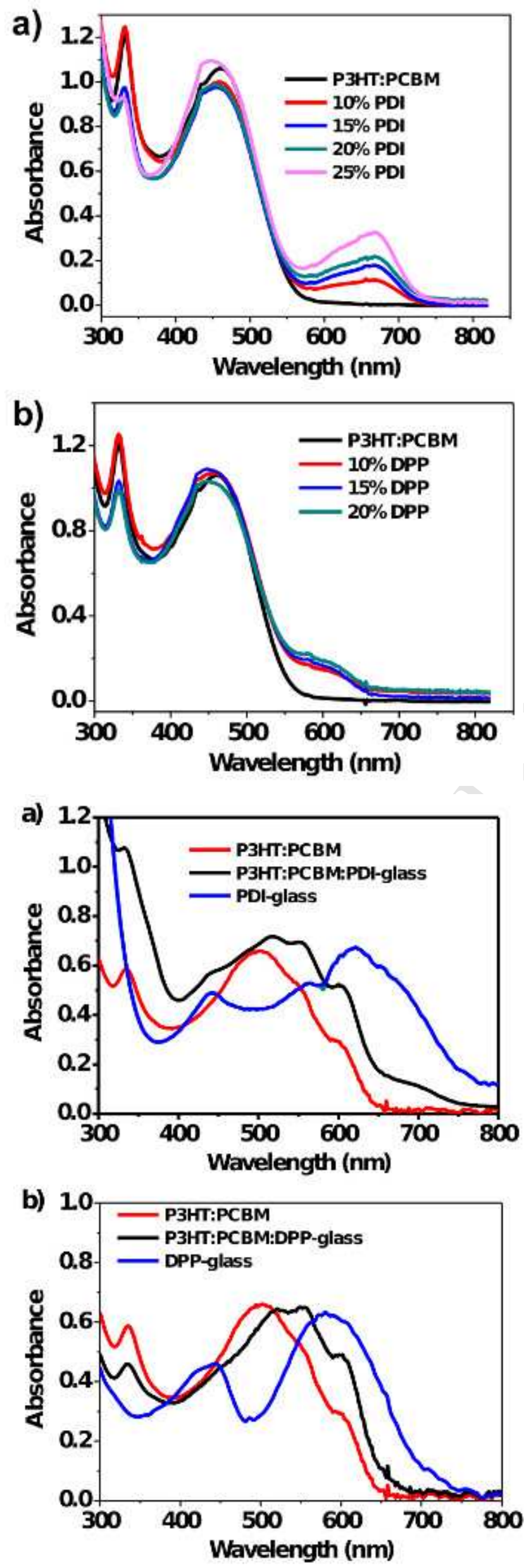

Figure 2. UV-Visible spectra for the 1:1 P3HT:PCBM blend in dichlorobenzene solution $(0.5 \mathrm{wt} \%)$ and its respective ternary blends with various concentrations of (a) PDI-glass (10-25\%) and (b) DPP-glass (10-20\%).

As a thin film, the P3HT:PCBM blend shows an absorption spectrum similar to a superposition of that of its respective components (Figure 3), with bands at 340 and $515 \mathrm{~nm}$ due to the main $\pi-\pi^{*}$ transitions for PCBM and P3HT, and two vibronic absorption shoulders at 558 and $607 \mathrm{~nm}^{42}$ The addition of PDI-glass in the blend (Figure 3a) results in the appearance of two additional shoulders near 440 and $670 \mathrm{~nm}$ corresponding to both absorption bands of PDI-glass, as well as a slight increase in the absorption of the main band. Adding DPP-glass as ternary component results in a broadening and increase in intensity of the absorption band, especially in the $400-500 \mathrm{~nm}$ range. In both cases, the addition of a ternary component increases the absorption of the respective blends, in the case of PDI-glass the absorption range is extended up to $750 \mathrm{~nm}$, whereas in the case of DPP-glass stronger absorption is observed at lower visible wavelengths.

Figure 3. UV-Visible spectra for P3HT:PCBM thin films and their blends with (a) PDI-glass (20\%) and (b) DPP-glass $(15 \%)$. All films were deposited by spin-coating from dichlorobenzene solution and annealed at 110 for 30 minutes.

$\mathrm{X}$-ray diffraction was used to investigate the morphological changes resulting from the addition of PDI-glass or DPP-glass on the crystallinity of the P3HT:PCBM blends. Films of P3HT:PCBM blends along with their ternary blends with PDI-glass and DPP-glass were prepared using the same conditions as those used for device fabrication. X-ray diffraction (XRD) patterns for the control P3HT:PCBM blend without and with annealing at 110 for 30 minutes (Figure 4) show one major diffraction peak corresponding to the [100] plane at $2 \theta=5-7^{\circ}$, showing the first-order structure of P3HT with a d spacing of $1.7 \mathrm{~nm} .{ }^{43-44}$ Expectedly, annealing

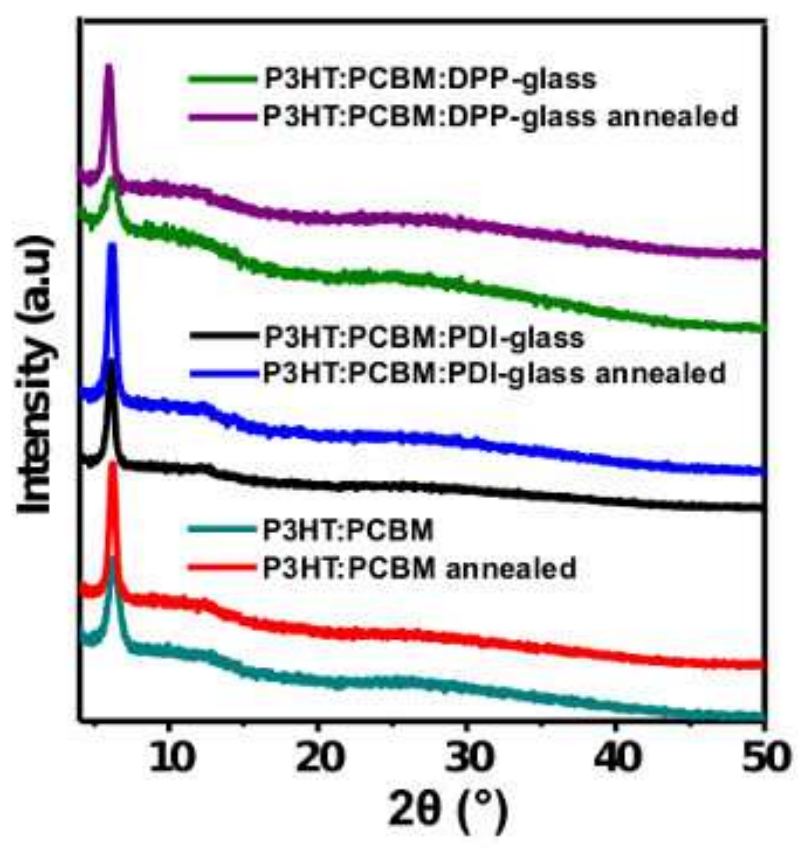


Figure 4. X-ray diffraction spectra for films of P3HT:PCBM and ternary blend films with PDI-glass or DPP-glass deposited by spin-coating from dichlorobenzene solution (with or without annealing at 110 for 30 minutes).

It is crucial for OPV cells to show an optimal performance that photo-induced charges be transferred rapidly from the donor to the acceptor. ${ }^{45}$ If the electrons generated in the working device are not transferred within a few femtoseconds, the excitons will decay to the ground state, instead emitting photoluminescence, which is detrimental to device performance. Photoluminescence quenching thus constitutes a useful tool to confirm electron transfer from the photo-excited donor to the acceptor. ${ }^{46}$ The photoluminescence spectra for the control P3HT:PCBM blend and its respective ternary blends with PDI-glass and DPP-glass (Figure 5a) show that while PCBM itself contributes to quench more than half of the photoluminescence of P3HT, the introduction of various concentrations of PDI-glass (10-25\%) results in an additional gradual decrease of the $\mathrm{P} 3 \mathrm{HT}$ photoluminescence, reaching saturation at $25 \%$. DPP-glass showed a similar behavior, reaching saturation at $15 \%$ (Figure $\mathrm{S} 1$ ).

The photoluminescence decay of the samples with time was also studied for various amounts of PDI-glass (Figure 5b). As observed, the blends exhibit quenching of both PL intensity and emission lifetime comparatively to P3HT:PCBM, which is more pronounced when increasing the ratio of PDI-glass, reaching a maximum at $15 \%$ PDI-glass. These results show that exciton dissociation and charge transfer are facilitated at the interface between P3HT and PCBM/PDI-glass. The quenching is dependent on the concentration of PDI-glass and

a)

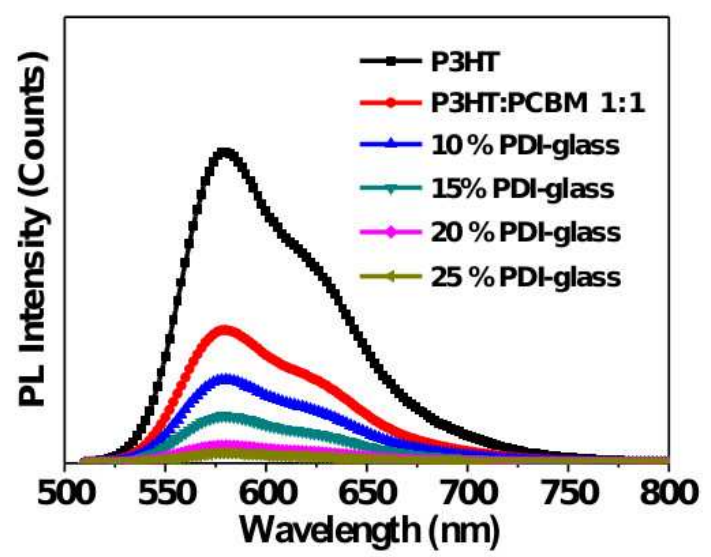

b)

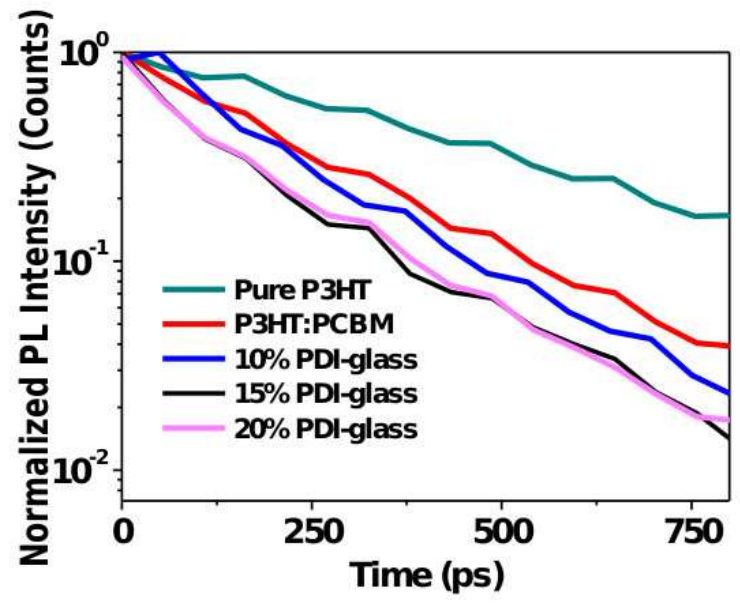

is predominantly attributed to electron transfer from $\mathrm{P} 3 \mathrm{HT}$ to the PCBM/PDI-glass interface. The curves were fitted (Figure S2) to yield the corresponding PL lifetimes for the different blends, which are listed in Table 1. The fluorescence decay rate is in the order P3HT>P3HT: PCBM>P3HT: PCBM: PDIglass, and decresases with increasing PDI-glass ratio until reaching a plateau at $15 \%$. This decrease in PL lifetime and PL intensity with increasing PDI-glass concentration in the blend leads to a decrease in charge recombination, and a smoother charge transfer, across the donor-acceptor interface.

Figure 5. a) Photoluminescence spectra for P3HT, P3HT:PCBM and P3HT:PCBM:PDI-glass (10-25\%); b) timeresolved normalized photoluminescence spectra for $\mathrm{P} 3 \mathrm{HT}$, P3HT:PCBM and P3HT:PCBM:PDI-glass (10-20\%).

Table 1. Exciton lifetime $(\tau)$ for P3HT, P3HT:PCBM and P3HT:PCBM (10-20\%) measured from the fitting of timeresolved PL spectra.

\begin{tabular}{ll}
\hline Sample & $\boldsymbol{\tau}(\mathbf{p s})$ \\
\hline P3HT & $455 \pm 2$ \\
P3HT:PCBM 1:1 & $231 \pm 3$ \\
P3HT:PCBM:10\% PDI-glass & $210 \pm 2$ \\
P3HT:PCBM:15\% PDI-glass & $182 \pm 1$ \\
P3HT:PCBM:20\% PDI-glass & $178 \pm 1$ \\
\hline
\end{tabular}

The surface morphology of the blend films was compared by AFM (Figure 6). The control P3HT:PCBM film shows a surface littered with small grains ranging from 100-200 nm in diameter and 3-5 $\mathrm{nm}$ in height (Figure 6a). Annealing at 110

for 30 minutes yielded a similar morphology, but with increased average surface roughness (Figure 6b). The introduction of PDI-glass showed similar morphologies, but with a gradual increase in both overall surface roughness and in average grain size, which range from $250-500 \mathrm{~nm}$ in diameter and $10-20 \mathrm{~nm}$ in height with $25 \%$ PDI-glass (Figures 6i-j). However, whereas annealing of P3HT:PCBM blend films causes an increase in surface roughness, which is a result of a higher degree of crystallinity, ${ }^{47}$ the annealing of ternary blends with PDI-glass shows negligible impact on surface morphology. As surface topography has been shown to be important for optimal cell performance, ${ }^{48}$ the fact that the presence of PDI-glass as ternary component did not disturb morphology is encouraging. However, the higher surface roughness observed with higher PDI-glass ratios (25 $\%$ ) suggest that raising the ternary component ratio beyond an optimal concentration could be deleterious to cell performance. ${ }^{49}$ Similar observations were made with DPP- 
glass as ternary component (Figure S3).

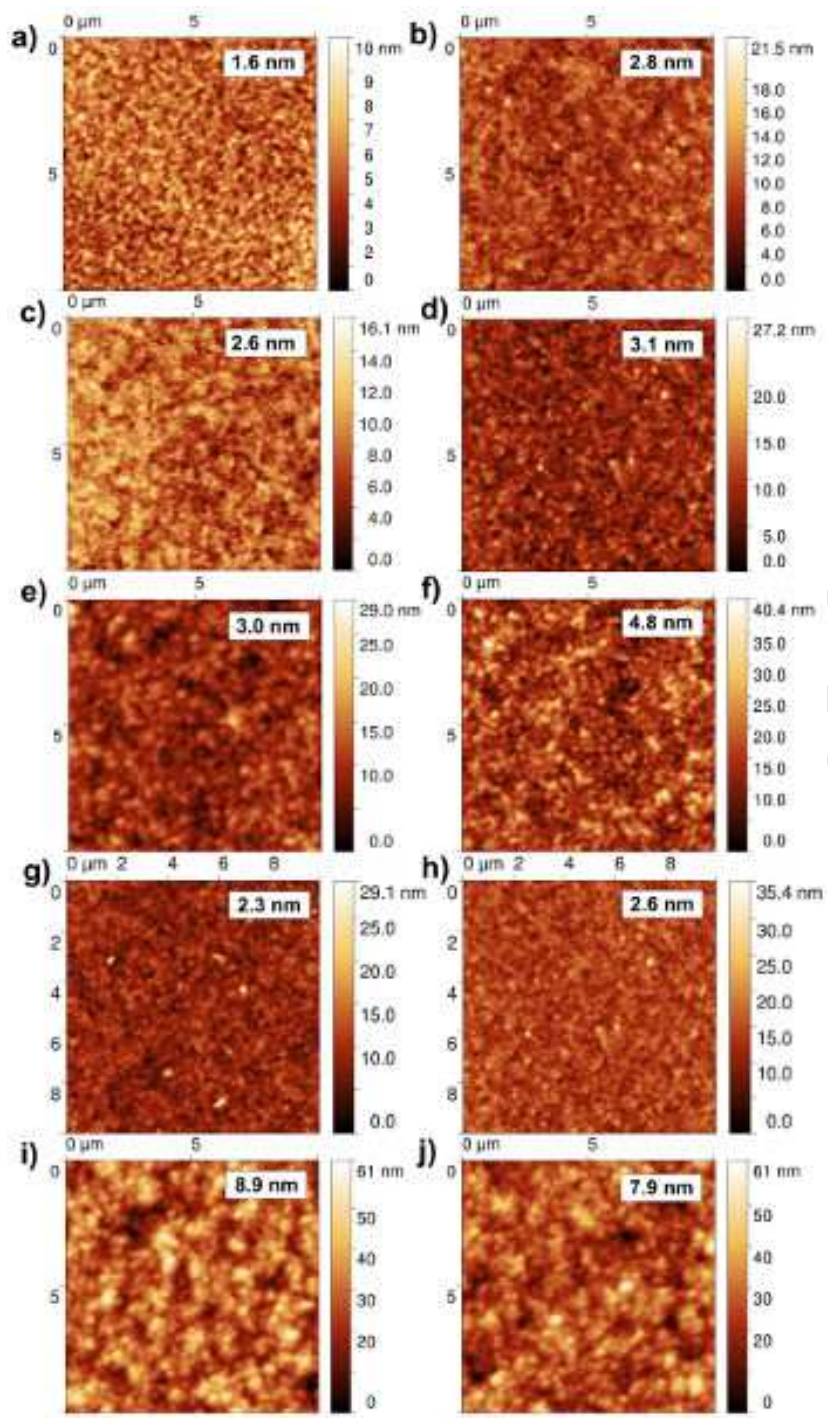

Figure 6. AFM topographic images $(20 \mu \mathrm{m} \times 20 \mu \mathrm{m})$ for the ternary blend films of PDI-glass in spin-coated from chlorobenzene, with or without annealing at $110{ }^{\circ} \mathrm{C}$ for 30 minutes. (a) $0 \%$, (b) $0 \%$ annealed, (c) $10 \%$ (d) $10 \%$ annealed, (e) $15 \%$, (f) $15 \%$ annealed, (g) $20 \%$, (h) $20 \%$ annealed, (i) $25 \%$, , j) $25 \%$ annealed.
Solution-processed organic photovoltaic cells with an inverted structure ITO/ZnO/P3HT:PCBM:glass/ $/ \mathrm{MoO}_{3} / \mathrm{Ag}$ were fabricated using $\mathrm{P} 3 \mathrm{HT}$ as donor and $\mathrm{PCBM}$ as acceptor in blend ratios of $1: 1$ by mass. The ternary blends were prepared by adding $10-25 \%$ by mass of either PDI-glass or DPP-glass. The current-voltage characteristics in the dark and under illumination for the devices are shown in Figure 7. The dark J-V curve in Figure 7 a shows that all devices show proper diode behavior with low leakage current under reverse bias and high forward dark current showing superior filmforming characteristics.

The device with $20 \%$ PDI-glass exhibits the lowest leakage current and highest forward current as compared to other concentrations, reflecting optimal PV performance. The power conversion efficiency $(\eta)$ of the devices was calculated from the open-circuit voltage $\left(\mathrm{V}_{\mathrm{oc}}\right)$, short-circuit current density $\left(\mathrm{J}_{\mathrm{sc}}\right)$ and fill factor $(\mathrm{FF})$ values with the following equation: PCE $(\eta)=J_{s c} \times V_{o c} \times F F / P_{\text {in }}$, where $P_{\text {in }}$ represents the power of incident light $\left(\mathrm{mWcm}^{-2}\right)$. The fill factor was calculated from the open-circuit voltage $\left(\mathrm{V}_{\mathrm{oc}}\right)$, short-circuit current $\mathrm{I}_{\mathrm{sc}}$, and maximum power $\left(\mathrm{P}_{\max }\right)$ values according to the following equation: $\mathrm{FF}=\mathrm{P}_{\mathrm{max}} / \mathrm{J}_{\mathrm{sc}} \times \mathrm{V}_{\mathrm{oc}}=$ $J_{\text {max }} \times V_{\text {max }} / J_{\text {sc }} \times V_{\text {oc }}$, where $J_{\text {max }}$ and $V_{\text {max }}$ are the current density and voltage at maximum power, respectively. The photovoltaic parameters of the inverted devices fabricated with P3HT:PCBM:PDI-glass were corrected using values measured with a calibrated solar simulator and are reported in Table 2. The details of the calibration correction are shown in Tables S1 \& S2 (Supporting Information). Control devices fabricated with a binary P3HT:PCBM blend showed a typical PCE of $2.81 \%$ with a short-circuit current of $8.70 \mathrm{mAcm}^{-2}$, an open-circuit voltage of $0.60 \mathrm{~V}$, and a fill factor of 0.54 . These values are close to average reported values with P3HT:PCBM. ${ }^{50}$ It should be noted that although higher efficiencies have been reported with P3HT:PCBM, even using a similar device configuration ${ }^{51}$, it has been shown that various processing parameters, including the brand of P3HT used, can impact device efficiency. ${ }^{13}$ For the present study, inverted devices were selected because of their ease of fabrication and stability under ambient conditions. ${ }^{52}$ Incorporating PDI-glass in weight ratios ranging from 10 to $25 \%$ in the P3HT:PCBM active layer led to significant enhancements in the $\mathrm{J}_{\mathrm{sc}}$ and PCE as compared to the control device. The device containing 20\% PDI-glass as ternary component resulted in the highest PCE of $3.89 \%$ with $\mathrm{J}_{\mathrm{sc}}$ $11.13 \mathrm{mAcm}^{-2}, \mathrm{~V}_{\text {oc }} 0.66 \mathrm{~V}$ and fill factor 0.53 . This represents a $38 \%$ enhancement in conversion efficiency relative to P3HT:PCBM. Increasing the PDI-glass ratio above $20 \%$, caused a decrease in device performance, which was still higher than that of the control device. This is possibly due to an increase in series resistance associated with a more uneven surface morphology. The effect of annealing temperature was investigated by comparing the performance of devices annealed at $110{ }^{\circ} \mathrm{C}$ for 30 minutes and compared with that of unannealed devices (Figure S5). Annealing resulted in an increase of $26 \%$ in current density and an increase of $19 \%$ in 
PCE. In comparison, for P3HT:PCBM alone, annealing leads to an increase in PCE of $20 \% .{ }^{53}$ Interestingly, even unannealed devices incorporating $20 \%$ PDI-glass showed a better performance than annealed devices with P3HT:PCBM. This increase in PV performance after annealing is attributed to increase in crystallinity, leading to higher charge mobility, thereby resulting in higher short-circuit current. ${ }^{54}$ Annealing at different temperatures or for longer periods of time did not result in any significant improvement.

Similarly, the current-voltage characteristics for the ternary blend devices with DPP-glass in the dark and under illumination were studied and are shown in (Figure 8). The dark J-V curves in (Figure 8a) reveal that all the devices show proper diode behavior with lower leakage current in the reverse bias showing high-quality films. The device with 15 $\%$ optimal concentration of PDI-glass (15\%) exhibits relatively lower leakage current, reflecting superior PV performance. The PV parameters for the ternary blend devices with DPP-glass are reported in Table 3. The device with optimal concentration of DPP-glass (15\%) shows an efficiency of $3.82 \%$ with a current density of $11.85 \mathrm{mAcm}^{-2}$, an open-circuit voltage of $0.62 \mathrm{~V}$ and a fill factor of 0.52 . This corresponds to an efficiency enhancement of $36 \%$ relative to P3HT:PCBM, which is similar to the enhancement observed with PDI-glass. However, increasing the concentration of DPP-glass ratio beyond the optimal concentration (15\%) did not show any improvement. Instead, the performance decreases together with an increase in series resistance. It is likely due to the DPP-glass hindering the crystallization of P3HT, as evidenced by XRD.
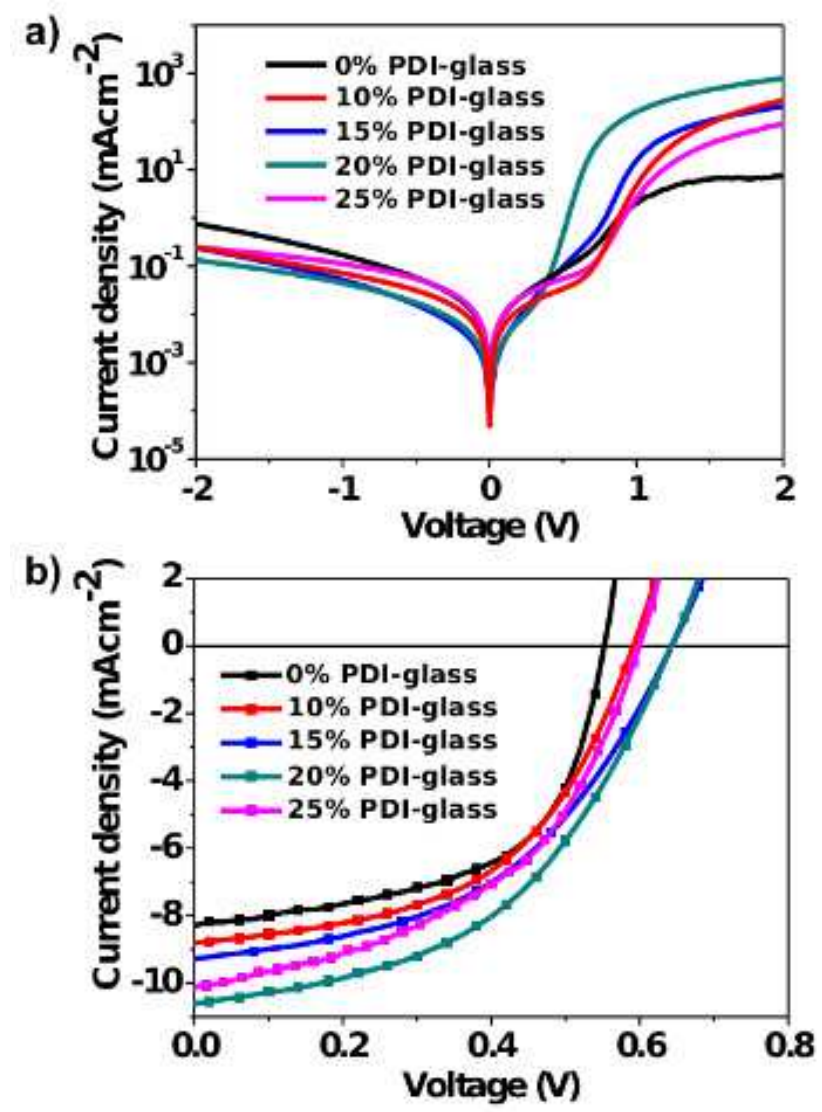

Figure 7. Current-voltage characteristics of ITO/ZnO/P3HT:PCBM:PDI-glass (0-25 wt $\%$ ) $/ \mathrm{MoO}_{3} / \mathrm{Ag}$ (a) in the dark, and (b) under illumination with an irradiance of $100 \mathrm{mWcm}^{-2}$.

Table 2. Current density $\left(\mathrm{J}_{\mathrm{sc}}\right)$, open-circuit voltage $\left(\mathrm{V}_{\mathrm{oc}}\right)$, fill factor(FF) and power conversion efficiency (PCE) of ITO/ZnO/P3HT:PCBM:PDI-glass (0-25\%)/ $\mathrm{MoO}_{3} / \mathrm{Ag}$ devices under illumination with an intensity of $100 \mathrm{mWcm}^{-2}$, with or without annealing at $110{ }^{\circ} \mathrm{C}$ for 30 minutes. The values were corrected according to a calibrated light source.

\begin{tabular}{|c|c|c|c|c|c|c|}
\hline $\begin{array}{l}\% \\
\text { Glass }\end{array}$ & PDI- & $\begin{array}{l}\text { Thermal } \\
\text { Annealing }\end{array}$ & $\begin{array}{l}\mathbf{J}_{\mathrm{sc}} \\
\left(\mathrm{mAcm}^{-2}\right)\end{array}$ & $\mathbf{V}_{\text {oc }}(\mathbf{V})$ & FF & PCE (\%) \\
\hline 0 & & Yes & 8.70 & 0.58 & 0.54 & $2.80 \pm 0.01$ \\
\hline 10 & & Yes & 9.24 & 0.61 & 0.52 & $2.86 \pm 0.07$ \\
\hline 15 & & Yes & 9.73 & 0.65 & 0.51 & $3.16 \pm 0.06$ \\
\hline 20 & & No & 9.33 & 0.62 & 0.50 & $2.90 \pm 0.07$ \\
\hline 20 & & Yes & 11.13 & 0.66 & 0.53 & $3.86 \pm 0.03$ \\
\hline 25 & & Yes & 10.63 & 0.62 & 0.47 & $3.02 \pm 0.06$ \\
\hline
\end{tabular}


a)
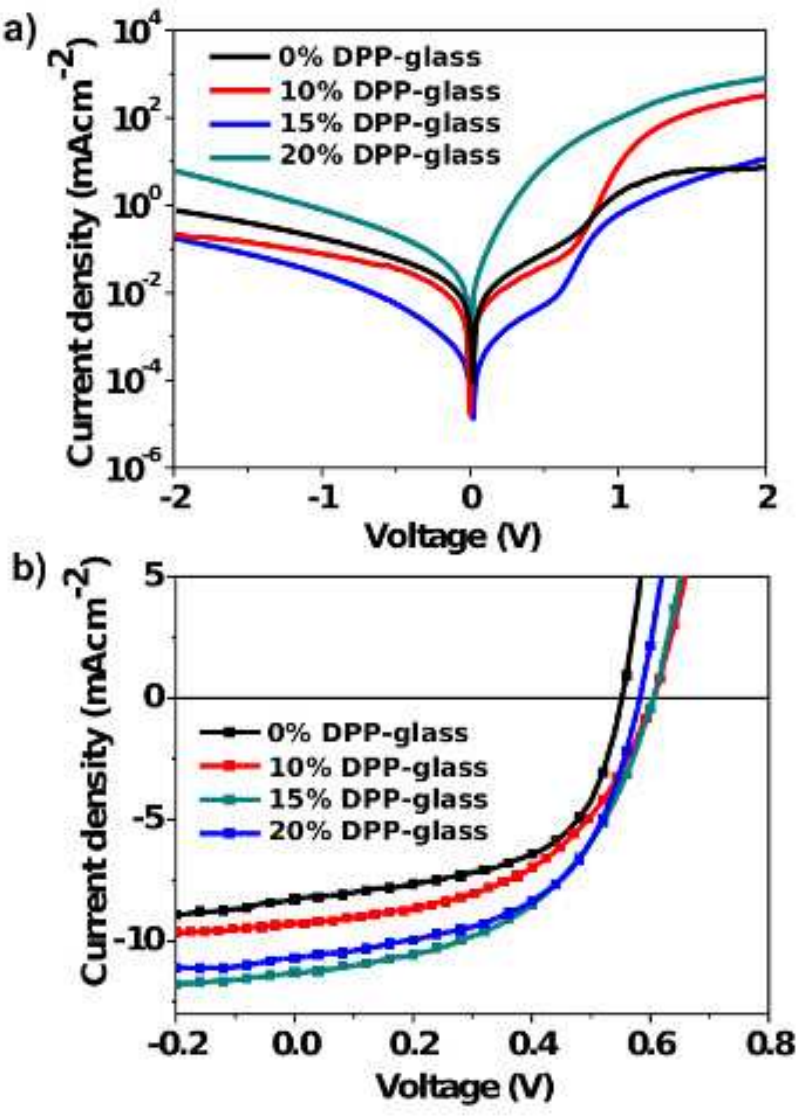

Figure 8. Current-voltage characteristics of ITO/ZnO/P3HT:PCBM:DPP-glass (0-20 wt $\%) / \mathrm{MoO}_{3} / \mathrm{Ag}$ (a) in the dark, and (b) under illumination with an irradiance of $100 \mathrm{mWcm}^{-2}$.

Table 3. Current density $\left(\mathrm{J}_{\mathrm{sc}}\right)$, open-circuit voltage $\left(\mathrm{V}_{\mathrm{oc}}\right)$, fill factor(FF) and power conversion efficiency (PCE) of ITO/ZnO/P3HT:PCBM:DPP-glass (0-20\%)/ $\mathrm{MoO}_{3} / \mathrm{Ag}$ devices under illumination with an intensity of $100 \mathrm{mWcm}^{-2}$, with annealing at $110{ }^{\circ} \mathrm{C}$ for 30 minutes. The values were corrected according to a calibrated light source.

\begin{tabular}{|c|c|c|c|c|c|}
\hline $\begin{array}{l}\% \quad \text { DPP- } \\
\text { Glass }\end{array}$ & $\begin{array}{l}\text { Thermal } \\
\text { Annealing }\end{array}$ & $\begin{array}{l}\mathbf{J}_{\mathrm{sc}} \\
\left.(\mathbf{m A c m})^{-2}\right)\end{array}$ & $\mathbf{V}_{\text {oc }}(\mathbf{V})$ & $\mathbf{F F}$ & PCE (\%) \\
\hline 0 & Yes & 8.70 & 0.60 & 0.54 & $2.80 \pm 0.01$ \\
\hline 10 & Yes & 9.79 & 0.62 & 0.52 & $3.00 \pm 0.02$ \\
\hline 15 & Yes & 11.85 & 0.62 & 0.51 & $3.80 \pm 0.04$ \\
\hline 20 & Yes & 11.23 & 0.66 & 0.53 & $3.31 \pm 0.05$ \\
\hline
\end{tabular}

Furthermore, the IPCE spectrum of the device with an optimal concentration of PDI-glass (20\%) was measured and compared with that of a P3HT:PCBM device (Figure 9). It is observed that while the IPCE spectrum for the P3HT: PCBM device covers a broad range of wavelengths from 300 to 670 $\mathrm{nm}$, both ternary blend devices incorporating PDI-glass and DPP-glass show an additional photocurrent in the range 660$760 \mathrm{~nm}$, highlighting the contribution of both PDI-glass and DPP-glass towards light harvesting. Furthermore, the IPCE value at $540 \mathrm{~nm}$ corresponding to the absorption of $\mathrm{P} 3 \mathrm{HT}$ also increases from $55 \%$ in the binary device to $62 \%$ in the presence of PDI-glass and $61 \%$ with DPP-glass, suggesting that both glass-forming acceptors promote charge generation from the excitons in $\mathrm{P} 3 \mathrm{HT}$. $^{16,55}$

These results definitely reveal insights on how these ternary blends function. Both PDI-glass and DPP-glass act as electron acceptors with $\mathrm{P} 3 \mathrm{HT}$, thereby suggesting that their ternary blend cells with P3HT:PCBM function via the charge transfer mechanism, in which free charge carriers generated by the guest acceptor are rapidly transferred to PCBM. Interestingly, while DPP-glass possesses a significantly higher mobility (and consequently, photovoltaic performance) than PDI-glass, in both cases, the enhancement observed is similar. This is likely due to the fact that since the guest acceptors are glasses, they do not form individual domains, instead occupying the interfaces between the P3HT and PCBM domains. Electrons therefore must only travel short distances in the guest acceptors as compared to PCBM, in which they have a sufficient mobility. This mitigates the negative impact that the low-mobility glasses could have on device performances.

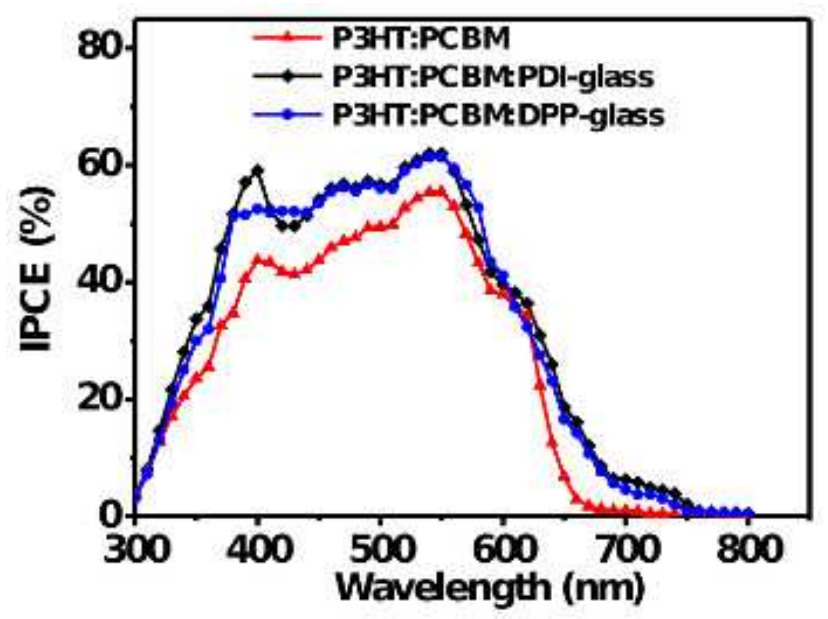

Figure 9. IPCE spectra of P3HT:PCBM (black), P3HT:PCBM:PDI-glass (20\%) and P3HT:PCBM:DPP-glass $(15 \%)$ devices. All the devices were thermally annealed at 100 for 30 minutes.

To test the stability of the ternary devices, one set of ternary blend devices with PDI-glass $(15 \%)$ was exposed to air at ambient temperature in the dark (without any encapsulation). The device retained a significant portion of its original efficiency after exposure in air for 40 days, only losing $25 \%$ of its efficiency (from 3.0 to $2.4 \%$ ), as shown in Figure S6 
(Supporting Information). While the devices are slightly less stable than binary devices with P3HT:PCBM, which lose approximately $20 \%$ of their efficiency under similar conditions, ${ }^{53}$ these ternary devices are significantly more stable than several previously reported ternary systems. This shows that the incorporation of glass-forming acceptors is beneficial to device stability, despite previous reports in the literature where the incorporation of a ternary component resulted in a lower device stability. ${ }^{56}$

\section{Conclusions}

The incorporation of glass-forming acceptors as ternary components in the active layer of P3HT:PCBM photovoltaic cells was studied herein with two previously reported acceptors: PDI-glass and DPP-glass. It was found that these materials did not aggregate in the blend films and preferentially locate at the interface between the P3HT and PCBM domains without disrupting the crystallization of P3HT. Their location at the interface results in an enhancement of the photocurrent generation by both direct photo-excitation and effective charge separation. The devices function via the charge transfer mechanism. Conversion efficiency enhancements of $38 \%$ and $36 \%$ were observed in the devices with optimal concentrations of PDI-glass and DPP-glass, respectively, as compared to the reference P3HT:PCBM device. Furthermore, the ternary devices showed only $20 \%$ degradation after 40 days of storage under ambient conditions in the dark, thereby showing appreciable stability towards moisture and oxygen. This architecture opens the door towards significant improvements in the performance of other organic photovoltaic cells by incorporating amorphous acceptors as ternary components.

\section{Acknowledgements}

The authors would like to acknowledge the Canadian Defence Academic Research Programme (CDARP) of RMC and the Natural Sciences and Engineering Research Council (NSERC) Discovery Grants program (RGPIN-2015-05485) and CREATE program (Novel Chiral Materials: An International Effort in Research and Education) for supporting this research. We would also like to thank Dr. Soren Mellerup for access to the equipment for fluorescence measurements.

\section{Supporting Information}

DSC thermograms of compounds $\mathbf{2 - 4}$, cyclic voltammograms of compound $\mathbf{4}$, additional current-voltage curves for photovoltaic cells, calibrated data for PV cells, electron mobility measurement for compounds 4, NMR spectra of compounds 1-4.

\section{Notes and references}

¥ Marvin was used for drawing, displaying and characterizing chemical structures, substructures and reactions, Marvin 15.1.12, 2015, ChemAxon (www.chemaxon.com).

1 Bloking, J.T.; Han, X.; Higgs, A.T.; Kastrop, J.P.; Pandey, L.; Norton, J.E.; Risko, C.; Chen, C.E.; Brédas, J.-L.; McGehee, M.D.; Sellinger, A. Solution-Processed Organic Solar Cells with Power Conversion Efficiencies of 2.5\% using Benzothiadiazole/Imide-Based Acceptors, Chem. Mater. 2011, $23,5484-5490$.

2 Honda, S.; Nogami, T.; Ohkita, H.; Benten, H.; Ito, S. Improvement of the light-harvesting efficiency in polymer/fullerene bulk heterojunction solar cells by interfacial dye modification, ACS Appl. Mater. Interfaces 2009, 1, 804810 .

3 Cnops, K.; Rand, B.P.; Cheyns, D.; Verreet, B.; Empl, M.A.; Heremans, P. $8.4 \%$ efficient fullerene-free organic solar cells exploiting long-range exciton energy transfer, Nat. Commun. 2014, 5, 3406.

$4 \quad$ Lin, Y.; Ma, L.; Li, Y.; Liu, Y.; Zhu, D.; Zhan, X. A Solution-Processable Small Molecule Based on Benzodithiophene and Diketopyrrolopyrrole for HighPerformance Organic Solar Cells, Adv. Energ. Mater. 2013, 3, 1166-1170.

5 Sun, D.; Meng, D.; Cai, Y.; Fan, B.; Li, Y.; Jiang, W.; Huo, L.; Sun, Y.; Wang, Z. Non-Fullerene-Acceptor-Based Bulk-Heterojunction Organic Solar Cells with Efficiency over 7\%, J. Am. Chem. Soc. 2015, 137, 11156-11162.

6 Zhou, Y.; Ding, L.; Shi, K.; Dai, Y.Z.; Ai, N.; Wang, J.; Pei, J. A non-fullerene small molecule as efficient electron acceptor in organic bulk heterojunction solar cells, Adv. Mater. 2012, 24, 957-961.

7 Tang, Z.; Liu, B.; Melianas, A.; Bergqvist, J.; Tress, W.; Bao, Q.; Qian, D.; Inganas, O.; Zhang, F. A new fullerenefree bulk-heterojunction system for efficient high-voltage and high-fill factor solution-processed organic photovoltaics, $A d v$. Mater. 2015, 27, 1900-1907.

8 Murali, M.G.; Rao, A.D.; Yadav, S.; Ramamurthy, P.C. Narrow band gap conjugated polymer for improving the photovoltaic performance of P3HT:PCBM ternary blend bulk heterojunction solar cells, Polym. Chem. 2015, 6, 962-972.

9 Ma, W.; Yang, C.; Gong, X.; Lee, K.; Heeger, A.J. Thermally stable, efficient polymer solar cells with nanoscale control of the interpenetrating network morphology, Adv. Funct. Mater. 2005, 15, 1617-1622.

10 Brabec, C.J.; Gowrisanker, S.; Halls, J.J.; Laird, D.; Jia, S.; Williams, S.P. Polymer-fullerene bulk-heterojunction solar cells, Adv. Mater. 2010, 22, 3839-3856.

11 Liu, F.; Zhao, W.; Tumbleston, J.R.; Wang, C.; Gu, Y.; Wang, D.; Briseno, A.L.; Ade, H.; Russell, T.P. Understanding the Morphology of PTB7:PCBM Blends in Organic Photovoltaics, Adv. Energ. Mater. 2013, 4, 1301377.

12 Park, S.H.; Roy, A.; Beaupré, S.; Cho, S.; Coates, N.; Moon, J.S.; Moses, D.; Leclerc, M.; Lee, K.; Heeger, A.J. Bulk heterojunction solar cells with internal quantum efficiency approaching 100\%, Nat. Photon. 2009, 3, 297-302.

13 Dennler, G.; Scharber, M.C.; Brabec, C.J. PolymerFullerene Bulk-Heterojunction Solar Cells, Adv. Mater. 2009, 21, 1323-1338.

14 Lim, B.; Bloking, J.T.; Ponec, A.; McGehee, M.D.; Sellinger, A. Ternary bulk heterojunction solar cells: addition of soluble NIR dyes for photocurrent generation beyond $800 \mathrm{~nm}$, ACS Appl. Mater. Interfaces 2014, 6, 6905-6913.

15 Chen, G.; Sasabe, H.; Igarashi, T.; Hong, Z.; Kido, J. Squaraine dyes for organic photovoltaic cells, J. Mater. Chem. A 2015, 3, 14517-14534.

16 Khlyabich, P.P.; Burkhart, B.; Thompson, B.C. 
Efficient ternary blend bulk heterojunction solar cells with tunable open-circuit voltage, J. Am. Chem. Soc. 2011, 133, 14534- 14537

17 Lee, J.U.; Kim, Y.D.; Jo, J.W.; Kim, J.P.; Jo, W.H. Efficiency enhancement of P3HT/PCBM bulk heterojunction solar cells by attaching zinc phthalocyanine to the chain-end of P3HT, J. Mater. Chem. 2011, 21, 17209.

18 Yang, L.; Yan, L.; You, W. Organic Solar Cells beyond One Pair of Donor-Acceptor: Ternary Blends and More, $J$. Phys. Chem. Lett. 2013, 4, 1802-1810.

19 Mulherin, R.C.; Jung, S.; Huettner, S.; Johnson, K.; Kohn, P.; Sommer, M.; Allard, S.; Scherf, U.; Greenham, N.C. Ternary photovoltaic blends incorporating an all-conjugated donor-acceptor diblock copolymer, Nano Lett. 2011, 11, 48464851 .

20 Peet, J.; Tamayo, A.B.; Dang, X.-D.; Seo, J.H.; Nguyen, T.-Q. Small molecule sensitizers for near-infrared absorption in polymer bulk heterojunction solar cells, Appl. Phys. Lett. 2008, 93, 163306.

21 Huang, J.-S.; Goh, T.; Li, X.; Sfeir, M.Y.; Bielinski, E.A.; Tomasulo, S.; Lee, M.L.; Hazari, N.; Taylor, A.D Polymer bulk heterojunction solar cells employing Förster resonance energy transfer, Nat. Photon. 2013, 7, 479-485.

22 Liu, T.; Huo, L.; Sun, X.; Fan, B.; Cai, Y.; Kim, Y.; Kim, J.Y.; Choi, H.; Sun, Y. Ternary Organic Solar Cells Based on Two Highly Efficient Polymer Donors with Enhanced Power Conversion Efficiency, Adv. Energ. Mater. 2016, 6, 1502109.

23 An, Q.; Zhang, F.; Yin, X.; Sun, Q.; Zhang, M.; Zhang, J.; Tang, W.; Deng, Z. High-performnce alloy modelbased ternary small molecule solar cells, Nano Energy 2016 , 30, 276-282.

24 An, Q.; Zhang, F.; Zhang, J.; Tang, W.; Deng, Z.; Hu, B. Versatile ternary organic solar cells: a critical review, Energ Env. Sci. 2016, 9, 281-322.

25 Bi, P.Q.; Wu, B.; Zheng, F.; Xu, W.L.; Yang, W.Y.; Feng, L.; Zhu, F.; Hao, X.T. An Obvious Improvement in the Performance of Ternary Organic Solar Cells with "Guest" Donor Present at the "Host" Donor/Acceptor Interface, ACS Appl. Mater. Interfaces 2016, 8, 23212-23221.

26 Zhao, W.; Li, S.; Zhang, S.; Liu, X.; Hou, J. Ternary Polymer Solar Cells based on Two Acceptors and One Donor for Achieving $12.2 \%$ Efficiency, Adv. Mater. 2017, 29 , 1604059.

27 Angell, C.A. Formation of glasses from liquids and biopolymers, Science 1995, 267, 1924.

28 Strohriegl, P.; Grazulevicius, J.V Charge Transporting Molecular Glasses, Adv. Mater. 2002, 14, 1439-1452.

29 Khilji, M.Y.; Khan, M.Z.; Qayyum, A. Organic materials for electronic and opto-electronic devices, 1999.

30 Adhikari, T.; Ghoshouni Rahami, Z.; Nunzi, J.-M ; Lebel, O. Synthesis, characterization and photovoltaic performance of novel glass-forming perylenediimide derivatives, Org. Electron. 2016, 34, 146-156.

31 Adhikari, T.; Nunzi, J.-M.; Lebel, O. Solid-state showdown: comparing the photovoltaic performance of amorphous and crystalline small-molecule diketopyrrolopyrrole acceptors. Org. Electron. 2017, 48, 230-240.

32 Adhikari, T.; Nunzi, J.-M.; Lebel, O. Towards amorphous solution-processed small-molecule photovoltaic cells by design, Org. Electron. 2017, 49, 382-392.

33 Li, Z.; Dong, Q.; Xu, B.; Li, H.; Wen, S.; Pei, J.; Yao, S.; Lu, H.; Li, P.; Tian, W. New amorphous small molecules Synthesis, characterization and their application in bulk heterojunction solar cells, Sol. Energ. Mater. Sol. Cells 2011 , 95, 2272-2280.

34 Bulut, I.; Lévêque, P.; Heinrich, B.; Heiser, T.;
Bechara, R.; Zimmermann, N.; Méry, S.; Ziessel, R.; Leclerc, $\mathrm{N}$. LUMO's modulation by electron withdrawing unit modification in amorphous TAT dumbbell-shaped molecules, $J$. Mater. Chem. A 2015, 3, 6620-6628.

35 Li, W.; Wang, D.; Wang, S.; Ma, W.; Hedström, S.; James, D.I.; Xu, X.; Persson, P.; Fabiano, S.; Berggren, M.; Inganäs, O.; Huang, F.; Wang, E. One-Step Synthesis of Precursor Oligomers for Organic Photovoltaics: A Comparative Study between Polymers and Small Molecules, ACS Appl. Mater. Interfaces 2015, 7, 27106-27114.

36 Adhikari, T.; Shahiduzzaman, M.; Yamamoto, K. Lebel, O.; Nunzi, J.-M. Interfacial modification of the electron collecting layer of low-temperature solution-processed organometallic halide photovoltaic cells using an amorphous perylenediimide, Sol. Energ. Mater. Sol. Cells 2017, 160, 294300 .

37 Gholamkhass, B.; Kiasari, N.M.; Servati, P. An efficient inverted organic solar cell with improved $\mathrm{ZnO}$ and gold contact layers, Org. Electron. 2012, 13, 945-953.

38 Adhikari, T.; Solanke, P.; Pathak, D.; Wagner, T.; Bureš, F.; Reed, T.; Nunzi, J.-M. T-Shaped Indan-1,3-dione derivatives as promising electron donors for bulk heterojunction small molecule solar cell, Opt. Mater. 2017, 69 , 312-317.

39 Kim, J.S.; Park, J.H.; Lee, J.H.; Jo, J.; Kim, D.-Y.; Cho, K. Control of the electrode work function and active layer morphology via surface modification of indium tin oxide for high efficiency organic photovoltaics, Appl. Phys. Lett. 2007, $91,112111$.

40 Li, L.; Lu, G.; Yang, X. Improving performance of polymer photovoltaic devices using an annealing-free approach via construction of ordered aggregates in solution, J. Mater. Chem. 2008, 18, 1984-1990.

41 Falke, S.; Eravuchira, P.; Materny, A.; Lienau, C. Raman spectroscopic identification of fullerene inclusions in polymer/fullerene blends, J. Raman Spectrosc. 2011, 42, $1897-$ 1900 .

42 Sahare, S.; Veldurthi, N.; Datar, S.; Bhave, T. Photon assisted conducting atomic force microscopy study of nanostructured additives in P3HT:PCBM, RSC Adv. 2015, 5, 102795 .

43 Aloui, W.; Adhikari, T.; Nunzi, J.-M.; Bouazizi, A.; Khirouni, K. Effect of thermal annealing on the electrical properties of P3HT: $\mathrm{PC}_{70} \mathrm{BM}$ nanocomposites, Mater. Sci. Semicond. Process. 2015, 39, 575-581.

$44 \quad$ Aloui, W.; Adhikari, T.; Nunzi, J.-M.; Bouazizi, A. Effect of thermal annealing on the structural, optical and dielectrical properties of $\mathrm{P} 3 \mathrm{HT}: \mathrm{PC}_{70} \mathrm{BM}$ nanocomposites, Mater. Res. Bull. 2016, 78, 141-147.

45 Goutam, P.J.; Singh, D.K.; Iyer, P.K. Photoluminescence Quenching of Poly(3-hexylthiophene) by Carbon Nanotubes, J. Phys. Chem. C 2012, 116, 8196-8201.

46 Nikitenko, S.; Mayorova, J.; Troshin, P. Lyubovskaya, R.; Kaplunov, M. Photoluminescence quenching study of composites comprising novel fullerene-based acceptors and MDMO-PPV, Mol. Cryst. Liq. Cryst. 2007, 468, $239 /[591]-244 /[596]$.

47 Seidler, N.; Lazzerini, G.M.; Li Destri, G.; Marletta, G.;Cacialli, F. Enhanced crystallinity and film retention of P3HT thin-films for efficient organic solar cells by use of preformed nanofibers in solution, J. Mater. Chem. C 2013, I, 7748 .

48 Hedley, G.J.; Ward, A.J.; Alekseev, A.; Howells, C.T.; Martins, E.R.; Serrano, L.A.; Cooke, G.; Ruseckas, A.; Samuel, I.D. Determining the optimum morphology in highperformance polymer-fullerene organic photovoltaic cells, Nat. Commun. 2013, 4, 2867. 
49 Min, J.; Ameri, T.; Gresser, R.; Lorenz-Rothe, M.; Baran, D.; Troeger, A.; Sgobba, V.; Leo, K.; Riede, M.; Guldi, D.M.; Brabec, C.J. Two similar near-infrared (IR) absorbing benzannulated aza-BODIPY dyes as near-IR sensitizers for ternary solar cells, ACS Appl. Mater. Interfaces 2013, 5, 56095616.

50 Dang, T.M.; Hirsch, L.; Wantz, G. P3HT:PCBM, Best Seller in Polymer Photovoltaic Research, Adv. Mater. 2011, 23, 3597-3602.

$51 \quad$ Holliday, S.; Ashraf, R.S.; Wadsworth, A.; Baran, D.; Yousaf, S.A.; Nielsen, C.B.; Tan, C.-H.; Dimitrov, S.D.; Shang, Z.; Gasparini, N.; Alamoudi, M.; Laquai, F.; Brabec, C.J.; Salleo, A.; Durrant, J.R.; McCulloch, I. High-efficiency nd airstable P3HT-based polymer solar cells with a new non-fullerene acceptor, Nat. Commun. 2016, 7, 11585.

52 Sahin, Y.; Alem, S.; de Bettignies, R.; Nunzi, J.-M Development of air stable polymer solar cells using an inverted gold-on-top anode structure. Thin Sol. Films 2005, 476, 340343.

53 Ryu, M.S.; Cha H.J.; Jang, J. Effects of thermal annealing of polymer:fullerene photovoltaic solar cells for high efficiency, Curr. Appl. Phys. 2010, 10, S206-S209

$54 \quad$ Holliday, S.; Ashraf, R.S.; Wadsworth, A.; Baran, D.; Yousaf, S.A.; Nielsen, C.B.; Tan, C.H.; Dimitrov, S.D.; Shang, Z.; Gasparini, N.; Alamoudi, M.; Laquai, F.; Brabec, C.J.; Salleo, A.; Durrant, J.R.; McCulloch, I. High-efficiency and airstable P3HT-based polymer solar cells with a new non-fullerene acceptor, Nat. Commun. 2016, 7, 11585.

55 Zhu, R.; Jiang, C.-Y.; Liu, B.; Ramakrishna, S. Highly Efficient Nanoporous $\mathrm{TiO}_{2}$-Polythiophene Hybrid Solar Cells Based on Interfacial Modification Using a Metal-Free Organic Dye, Adv. Mater. 2009, 21, 994-1000.

56 Hau, S.K.; Yip, H.-L.; Baek, N.S.; Zou, J.; O’Malley, K.; Jen, A.K.-Y. Air-stable inverted flexible polymer solar cells using zinc oxide nanoparticles as an electron selective layer, ACS Appl. Mater. Interfaces 2009, 1, 804-810. 
Two molecular glasses (PDI-glass and DPP-glass) were used as ternary acceptors in $\mathrm{P} 3 \mathrm{HT}: \mathrm{PC}_{61} \mathrm{BM}$ photovoltaic cells.

Efficiency enhancements of 38 and $36 \%$ were observed with 20 wt\% PDI-glass and 15 wt\% DPP-glass, respectively.

Both ternary acceptors enhanced performance through an increase in light absorption throughout the visible range.

The devices showed stability towards air without the need for encapsulation comparable to that of similar binary P3HT:PCBM devices. 
P3HT:PC 61 BM + 20\% PDl-glass

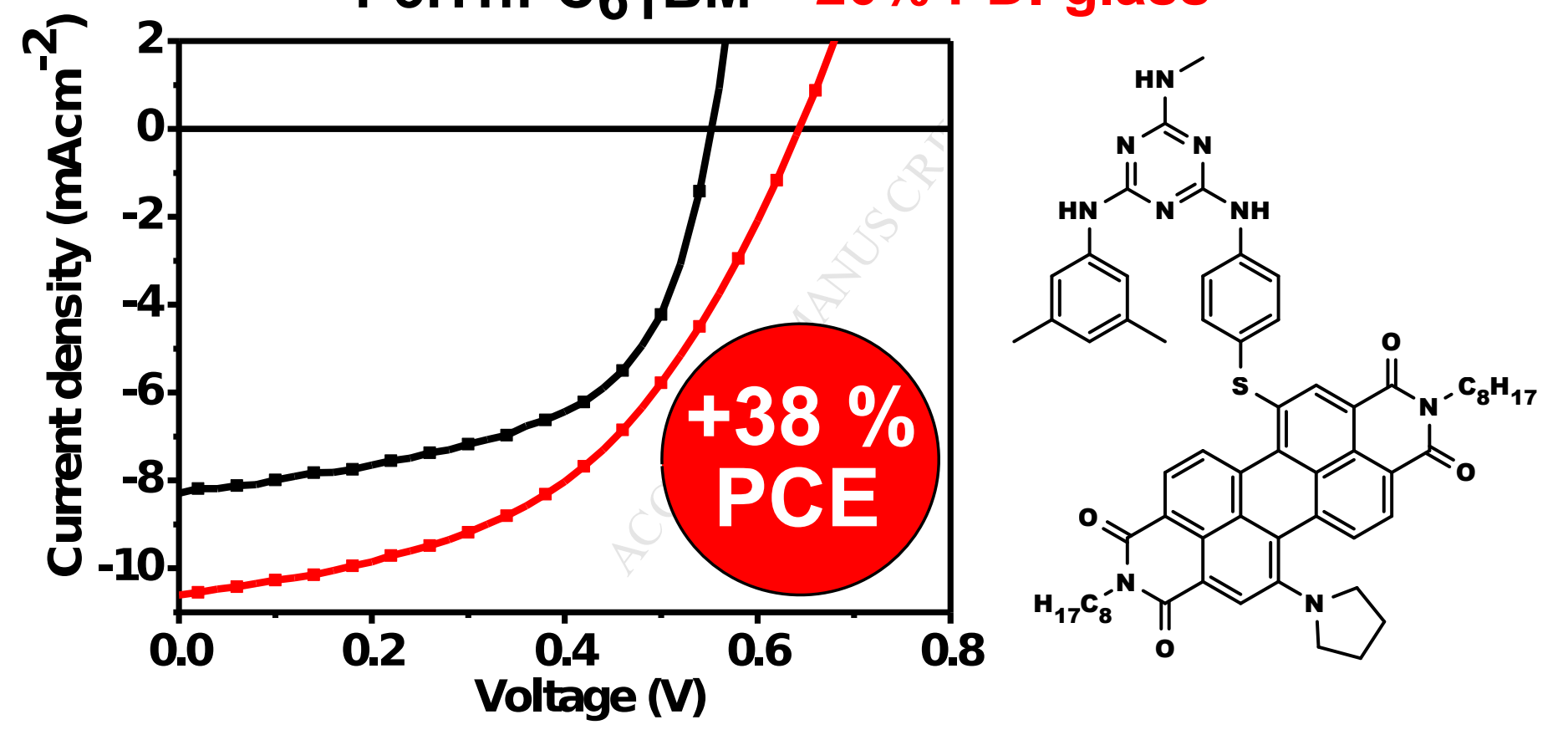

